\title{
Reactive Problem Solving and Proactive Development in Infrastructure Projects
}

\author{
Per Erik Eriksson ${ }^{1 *}$, Johan Larsson ${ }^{1}$ and Henrik Szentes ${ }^{2}$ \\ ${ }^{1}$ Luleå University of Technology, Sweden \\ ${ }^{2}$ Lund University, Sweden
}

*Corresponding author: Per Erik Eriksson, Luleå University of Technology, Sweden.

Received Date: July 05, 2019

Published Date: July 10, 2019

\section{Introduction}

The Swedish Transport Administration (STA) is by far the largest public client of transport infrastructure in Sweden. In addition to the responsibility of planning, construction, and operation and maintenance of public roads and railways, the STA has also been commissioned by the Swedish government to be responsible for the overarching and long-term planning of the infrastructure sector development, including promoting innovation and productivity development. This broad mission comprises major challenges, not least in the planning and execution of large infrastructure projects where a variety of different actors and technical systems are to be coordinated and deliver a sustainable project result. In this article, we discuss that these challenges require project participants to use their creative ability for both proactive and reactive development work to be able to deliver satisfactory project outcome. Further, we argue that these two types of development work can either hamper or support each other, depending on how they are managed. The arguments put forward in this article are based on results from several years of research in the fields of procurement, inter-organizational collaboration, innovation and organizational learning in the infrastructure sector.

\section{Challenges in Infrastructure Projects}

Large infrastructure projects are often particularly challenging from a project management perspective, since the project prerequisites often are characterized by high complexity and a number of uncertainties linked to, among other things, geology, a wide range of technical solutions, and the surrounding society [1, 2]. Examples of common challenges that must be dealt with in large infrastructure projects are prevailing soil conditions, temporary transport routes and traffic solutions, as well as a large number of stakeholders with different and sometimes competing demands and requirements. In addition to these project-specific challenges, the project actors must also relate to the continuously increasing expectations for cost-efficiency, quality and sustainability from the society. Not least, the global sustainability goals of Agenda 2030 have a significant influence. In addition, the STA has implemented a specific sustainability goal proclaiming that all their investment projects should be completely climate neutral in year 2045, which will put extensive demands on a more rapid development of sustainable solutions in individual projects [3].

\section{Need for Reactive Problem Solving}

In our study of five major complex construction projects, two main causes of reactive problem solving were identified, and they were particularly evident in infrastructure projects, namely uncertain geological conditions in land, rock and groundwater, and inadequately specified conditions and requirements in tendering documents [4]. These commonly occurring challenges often contribute to the emergence of sudden and unforeseen problems that need to be solved during the often time pressed production phase. These problems generate an extensive need for reactive problem solving and a high ability to deal with acute changes that may otherwise hinder the progress. These unplanned reactive work efforts are often the reasons why large infrastructure projects have difficulties in coping with time schedules and cost budgets defined in early project stages, which is a major problem in the infrastructure sector, not only in Sweden [5].

\section{Need for Proactive Development}

The more long-term and planned proactive development work has traditionally not received as much attention by actors in the infrastructure sector. Most projects rely on traditional and proven materials, methods and technical solutions to minimize risks for cost overruns, delays and accidents [6]. However, a trend where more projects and actors discuss innovation as something 
necessary in order to achieve a more sustainable development of the infrastructure sector can be discernible during the past few years. Innovation and development are needed to a greater extent in order to achieve the goals in Agenda 2030 and the high ambition for sustainability set by the STA. Each individual project can no longer focus solely on keeping time and budget, but also sustainability aspects (social, ecological, and economic) need increasing focus. Practitioners as well as researchers must realize that more risky innovation and development initiatives will also be required in individual projects. Therefore, in order to promote more sustainable development in the long-term, the need for proactive development, where more participants cooperate in the critical early design process, has increased in infrastructure projects.

\section{Reactive Problem Solving Inhibits Proactive Development}

A combined result from our prior studies show examples where the usually great need for reactive problem solving creates time pressure and crowds out more proactive development initiatives $[4,7,8]$. The project actors will focus on dramatic "fire-fighting" instead of spending time on proactive and reflective thinking. From a resource allocation perspective, too much focus is put on reactive problem solving, which is negative for proactive development. Another problem with reactive development efforts is that the solutions become more difficult to diffuse and re-use in other projects (compared to new solutions from proactive development), because they are developed under severe time pressure and are tailored to specific conditions and usually unique problems that have arisen in a specific project. From a sustainability perspective, the value of reactive solutions is therefore significantly lower than the value of proactively developed solutions that involve better chance to be reused in several projects and by several actors. Solutions from proactive development work can more often be evaluated and reused in similar projects in a more controlled way, which contributes to increased knowledge not only for those who contributed to the development but also to other actors in the infrastructure sector.

\section{Proactive Development Promotes Reactive Problem Solving}

Results from prior studies have, however, identified a potential positive correlation between proactive and reactive development work, given that the project participants are initially given time and opportunity to focus on proactive development. In our survey study [9], comprising 138 project managers within the STA, the results showed that joint proactive development work can promote reactive problem solving. By proactively working with co-creation and innovation, the project participants create a stronger foundation and buy-in for implementing new knowledge and technology. The project participants learn new things from and with each other at the same time as the trust between the actors increases, which means that the project organization as a whole is better prepared when the above-mentioned challenges and problems suddenly appear. The participants are more alert as well as better prepared to develop and choose alternative solutions that also explore solutions based on new types of knowledge. The fact that proactive development promotes reactive problem solving can in turn contribute to better project results and reduced time and cost overruns. The risk of serious delays is therefore considerably less in projects where the participants have prepared themselves in that form of proactive development work [9].

\section{How can we promote better use of creative abilities of project participants?}

Many types of innovations in the infrastructure sector are of a systemic nature, which means that they affect and are influenced by many actors and their activities [10]. Methods and technical solutions are complex and often consist of many work activities and subsystems that require interaction between many areas of competence during the development work. Our research results [8] show that collaboration is a vital foundation for proactive development work in complex infrastructure projects. This is in line with the fact that these innovative processes require the involvement and acceptance of multiple actors within the project (the system) in order to be implemented successfully [7]. Furthermore, our studies [4] have shown that early involvement of several actors in order to bring in both technical and production expertise in the design phase both provides a better overall solution that meets changing requirements, but can also provide innovative solutions that in the long-term can give us a more sustainable development of the infrastructure sector. In order to reap the benefits of early involvement, the client should also avoid locking in and specifying technical solutions in detail in tendering documents and instead focus on describing functional requirements to increase the degrees of freedom in the project.

Extensive time and cost pressure are emphasized as important obstacles to proactive development and innovation in our studies [8], which is in line with results from e.g. [6]. Our result shows that at high time pressure, the project participants prioritize existing technology and proven methods, partly to avoid surprises (and any delays due to failures) and partly because they simply do not have time to work with proactive development. In order to promote more proactive development, it may therefore be important, as a client, not to put in unnecessarily large time pressure in the contracts through e.g. payment plans, time bonuses or penalties. In addition, the cost budgets also are of great significance, since almost every proactive development must pay off in the individual project. This extreme emphasis of individual projects, therefore, inhibits most proactive development initiatives whose costs cannot be paid back during the current project. In exceptional cases, however, it has been found that project actors allocate central innovation money to proactive development in individual projects. This means that the development work is funded wholly or partly by strategic money in those cases where the innovation potential is clearly beyond the individual project [8]. This type of central funding of innovation work is quite unusual but positive for proactive development. Our results from a study of complex house projects identify joint risk management as another proactive activity that can facilitate 
the dialogue about what potential problems that may need to be addressed during the execution [11]. Most of the conclusions are equally relevant in infrastructure projects, and the earlier the risks are identified and discussed by the involved project actors, the easier it is to find solutions that do not jeopardize time or cost performance. In addition, a prolonged time schedule provides improved opportunities to find solutions that are better adapted for reuse in future projects.

\section{Concluding Remarks and Recommendations}

a. To reduce the need for reactive problem solving and increase opportunities and incentives for proactive development, we have concluded our overall results to a number of recommendations:

b. Improve the quality of the tendering documents and describing functional requirements instead of detailed specifications. Any technical solutions and working methods (including temporary traffic solutions) described in the tender documents should maintain a high quality so that unexpected problems with the solutions in a production phase are minimized.

c. Allocate central/strategic funding to innovation initiatives that show great potential for diffusion to and reuse in other projects.

d. Let the collaboration between key actors in the project become a foundation for proactive development. Since many innovations in the infrastructure sector are of a systemic nature, and concern many work activities and subsystems, collaboration between several actors is vital for successful proactive development work.

e. Acceptance from multiple project actors is necessary to succeed with the implementation of innovations of systemic nature. Early collaboration and participation of multiple actors are therefore important aspects in both reactive and proactive development work in infrastructure projects. f. Joint risk management in projects, as part of the collaborative arrangement between clients and suppliers, can be an effective way to enable proactive development work.

\section{Acknowledgement}

None.

\section{Conflict of Interest}

No conflict of interest.

\section{References}

1. Flyvbjerg B (2014) What you should know about megaprojects and why: An overview. Project management journal 45(2): 6-19.

2. Whyte J, Stasis A, Lindkvist C (2016) Managing change in the delivery of complex projects: Configuration management, asset information and big data. International Journal of Project Management 34(2): 339-351.

3. Trafikverket (2017) Klimatkrav.

4. Eriksson PE, Leiringer R, Szentes H (2017) The role of co-creation in enhancing explorative and exploitative learning in project-based settings. Project Management Journal 48(4): 22-38.

5. Cantarelli CC, Van Wee B, Molin EJ, Flyvbjerg B (2012) Different cost performance: different determinants? The case of cost overruns in Dutch transport infrastructure projects. Transport Policy 22: 88-95.

6. Rose T, Manley K (2012) Adoption of innovative products on Australian road infrastructure projects. Construction Management and Economics 30(4): 277-298.

7. Larsson L, Larsson J (2018) Sustainable Development in Project-Based Industries-Supporting the Realization of Explorative Innovation. Sustainability 10(3): 683.

8. Eriksson PE, Szentes H (2017) Managing the tensions between exploration and exploitation in large construction projects. Construction Innovation 17(4): 492 - 510.

9. Eriksson PE, Larsson J, Pesämaa O (2017) Managing complex projects in the infrastructure sector - A structural equation model for flexibilityfocused project management. International Journal of Project Management 35(8): 1512-1523.

10. Kähkönen K (2015) Role and Nature of Systemic Innovations in Construction and Real Estate Sector. Construction Innovation 15(2): 130-133.

11. Osipova E, Eriksson PE (2013) Balancing control and flexibility in joint risk management: Lessons learned from two construction projects. International Journal of Project Management 31(3): 391-399. 